\title{
Marked deterioration in the quality of life of patients with idiopathic pulmonary fibrosis during the last two years of life
}

\author{
K. Rajala ${ }^{1,2^{*}}$ D, J. T. Lehto ${ }^{3}$, E. Sutinen ${ }^{4}$, H. Kautiainen ${ }^{5}$, M. Myllärniemi $^{6}$ and T. Saarto ${ }^{7}$
}

\begin{abstract}
Background: Idiopathic pulmonary fibrosis (IPF) is a chronic disease with a high symptom burden and poor survival that influences patients' health-related quality of life (HRQOL). We aimed to evaluate IPF patients' symptoms and $\mathrm{HRQOL}$ in a well-documented clinical cohort during their last two years of life.

Methods: In April 2015, we sent the Modified Medical Research Council Dyspnea Scale (MMRC), the modified Edmonton Symptom Assessment Scale (ESAS) and a self-rating HRQOL questionnaire (RAND-36) to 300 IPF patients, of which 247 (82\%) responded. Thereafter, follow-up questionnaires were sent every six months for two years.

Results: Ninety-two patients died by August 2017. Among these patients, HRQOL was found to be considerably low already two years before death. The most prominent declines in HRQOL occurred in physical function, vitality, emotional role and social functioning $(p<0.001)$. The proportion of patients with MMRC scores $\geq 3$ increased near death. Breathlessness and fatigue were the most severe symptoms. Symptom severity for the following symptoms increased significantly and reached the highest mean scores during the last six months of life (numeric rating scale/ standard deviation): breathlessness (7.1/2.8), tiredness (7.0/2.3), dry mouth (6.0/3.0), cough (5.8/2.9), and pain with movement (5.0/3.5).

Conclusions: To our knowledge this is the first study demonstrating, that IPF patients experience remarkably low HRQOL already two years before death, especially regarding physical role. In addition, they suffer from severe breathlessness and fatigue. Furthermore, physical, social and emotional wellbeing deteriorate, and symptom burden increases near death. Regular symptom and HRQOL measurements are essential to assess palliative care needs in patients with IPF.
\end{abstract}

Keywords: Idiopathic pulmonary fibrosis, Palliative care, Health related quality of life, Symptoms

\section{Background}

Idiopathic pulmonary fibrosis (IPF) is a chronic disease with high morbidity and poor survival [1-4]. It occurs mainly in older adults, but the etiology of this progressive disease is still unknown [1]. Although the disease trajectory of IPF is variable, for many patients with IPF, survival is worse than many common malignancies. This necessitates early integration of palliative care to improve patients' quality of life (QOL) and to relieve symptoms in addition to disease-specific pharmacological treatment and lung transplant assessment [5-9].

\footnotetext{
* Correspondence: kaisa.rajala@fimnet.fi

${ }^{1}$ Department of Palliative Care, Comprehensive Cancer Center „, Helsinki

University Hospital, Paciuksenkatu 21, Po BOX 180, FI-00290 Helsinki, Finland

${ }^{2}$ Faculty of Medicine, University of Helsinki, Helsinki, Finland

Full list of author information is available at the end of the article
}

Existing studies have shown low health-related quality of life (HRQOL) in IPF patients. However, only few of them were prospective longitudinal studies, and most were relatively small in terms of sample size or were concentrated on pharmacological treatment [10-12]. IPF patients have been shown to suffer from lower HRQOL in real-life studies than in clinical studies $[12,13]$.

IPF patients suffer from many difficult symptoms, of which breathlessness and cough are the most common ones [8, 10, 14-20]. In addition, a substantial proportion of patients report anxiety, depression and pain [10, 21-26].

Dyspnea is a major contributor to HRQOL, and decreased HRQOL is associated with higher mortality [27, 28]. In a prospective Australian longitudinal registry study, impaired HRQOL was related to frequent respiratory 
hospitalizations and higher mortality [27]. However, to our knowledge, no previous studies have reported changes in HRQOL and symptom burden in connection with forthcoming death.

This study aimed to investigate IPF patients' HRQOL and symptom burden during the last two years of life in a prospective longitudinal follow-up study to recognise needs for palliative care and end-of-life care planning and to characterise their symptom burden in a unique follow-up setting.

\section{Materials and methods \\ Study population}

The FinnishIPF study is a national prospective clinical registry of IPF patients that was established in 2012. IPF diagnosis is based on the ATS/ERS 2011/2015 criteria [1, 6]. Nearly all Finnish IPF patients are initially evaluated at public university and central hospitals. Patients from these specialist centres with informed consent are included in the FinnishIPF registry, which consists of approximately $76 \%$ of all Finnish IPF patients [2]. Currently, the registry contains data from over 700 IPF patients.

All 300 patients registered in the FinnishIPF study in April 2015 were asked to participate in this substudy by sending an informed consent form together with the questionnaires. Those who did not respond within two weeks were called and reminded. Of the 300 registered patients, 247 (82\%) provided informed consent for this substudy, answered the first questionnaire and were included in this study. Subsequently, the same questionnaire was sent to the patients five times at six months intervals until August 2017.

\section{Data collection and questionnaires}

Disease and sociodemographic characteristics were collected from patient records and with a separate questionnaire (Additional file 1). These included the date of birth, sex, age, marital status, education, living conditions, physical activity level, the need for assistance in daily activities, the date of IPF diagnosis, smoking status, and comorbidities. Patients were asked the frequency of leisure time physical exercise that causes breathlessness and sweating for a minimum $30 \mathrm{~min}$ during the preceding six months. Death certificates were acquired from the "National Authority for Collecting and Compiling Statistics on Various Fields of Society and Economy".

The questionnaires regarding HRQOL and symptoms were the RAND 36-Item Health Survey (RAND-36), the Modified Medical Research Council Dyspnea Scale (MMRC), and the modified Edmonton Symptom Assessment Scale (ESAS).

RAND-36 [29] is a general QOL measurement tool with existing Finnish general population reference values [30].
RAND-36 is similar to the previously IPF-validated short-Form-36 [30-32]. RAND-36 is divided into eight health concepts $[29,30]$. Concepts are scored on a scale from 1 to 100, where a lower score indicates a worse HRQOL during the past four weeks $[29,30]$. The concepts are as follows: "general health" (five questions), "vitality" (four questions regarding energy level and tiredness), "bodily pain" (two questions), "physical functioning" (ten questions regarding the ability to take care of personal hygiene and the ability to move and exercise), "physical role" (four questions regarding role limitations due to physical health), "mental health" (five questions regarding mood, depression and anxiety), "emotional role" (three questions regarding role limitations due to emotional problems), and "social functioning" (two questions) [29, 30].

The self-rated MMRC measures the degree of disability that breathlessness causes during day-to-day activities on a scale from 0 to 4 , in which 0 indicates no breathlessness except during strenuous exercise, 1 indicates shortness of breath when walking up a slight hill or hurrying on a level, 2 indicates walking slower than people of same age on a level because of breathlessness or needing to stop to for breath when walking at one's own pace on a level, 3 indicates needing to stop for breath after a few minutes when walking on a level or after walking approximately $100 \mathrm{~m}$, and 4 indicates that the patient is too breathless to leave the house or is breathless when dressing or undressing $[33,34]$.

The ESAS is a numeric self-rating symptom-based scale that was originally developed to assess the symptoms of cancer patients $[35,36]$. Different symptoms are measured on Numeric Rating Scale (NRS) from 0 (no symptoms) to 10 (the worst possible symptoms) [36-38]. In this study, we used a version including 12 symptoms (pain at rest, pain with movement, tiredness, nausea, depression, anxiety, insomnia, loss of appetite, shortness of breath, cough, constipation, dry mouth, and overall wellbeing). There is a lack of evidence to recommend cut-off points for the ESAS. However, an NRS score $\geq 4$ is commonly used as a trigger for more comprehensive symptom assessment in clinical practice [39].

\section{Statistics and ethical aspects}

The study population characteristics are presented as the means with standard deviations (SD) or as counts with percentages. Patients' answers were grouped, according the time they answered from the aspect of death. The Kaplan-Meier method was used to estimate the cumulative mortality after the diagnosis. We used restricted cubic splines to detect a possible non-linear dependency. A nonlinear relationship between the RAND-36 domains, symptom severity, the MMRC and time before death were assessed by using 5-knot-restricted cubic spline 
random-effects regression models with appropriate distribution and link functions. Models included age and gender (only main effects) as covariates. A test of interaction between independent variables was performed through the MFPIgen command. The length of the distribution (months before death) of knots was located at the 5th, 27.5, 50th, 72.5, and 95th percentiles, which correspond to time before death of $-22,-15,-9,-5$ and -1 . The locations of the knots were determined by the percentiles recommended in Harrell's publication [40]. The normality of the variables was tested by using the Shapiro-Wilk test. The Finnish general population values for the eight Rand-36 domains were weighted to match the gender and age distribution of the study population, statistical analysis between our population and general population was not performed [30]. The Stata 15.0 [41] statistical package was used for the analysis.

The ethics committee of Helsinki University Central Hospital approved this study (381/13/03/01/2014). The Finnish National Institute for Health and Welfare (Dnro THL/1161/5.05.01/2012) approved the screening of hospital registries for patients with IPF. All participating patients provided written informed consent to participate to this specific study.

\section{Results}

Of the 247 patients included in the study 92 (37\%) died by August 2017 and were included in our follow-up cohort (Fig. 1).

The cumulative mortality of the patient cohort $(n=92)$ is presented in Fig. 2. The median overall survival was 4.4 years (IQR 3.1-5.7). Patient characteristics are shown in Table 1. A majority of the patients had comorbidities, of which cardiovascular diseases were the most common ones. None of the patients had lung cancer when entering the study, but two patients were diagnosed with lung cancer during the follow-up. Lung function measurements within the last six months of life were available in only 28 (30\%) of the patients (mean FVC 2.21 (SD 0.6), 57\%). Antifibrotic medication was used by $33(35 \%)$ of the patients.

The proportion of the patients who could not perform continuous moderate intensity physical exercise for at least 30 min during the previous six months increased from $34 \% 18-24$ months before death to $62 \%$ during the last six months of life. Six months before death, $67 \%$ of the patients reported needing assistance with their daily activities, while $18-24$ months before death this proportion was $56 \%$.

\section{Health-related quality of life}

Figure 3 shows the changes in the different dimensions of HRQOL measured with RAND-36 during two years

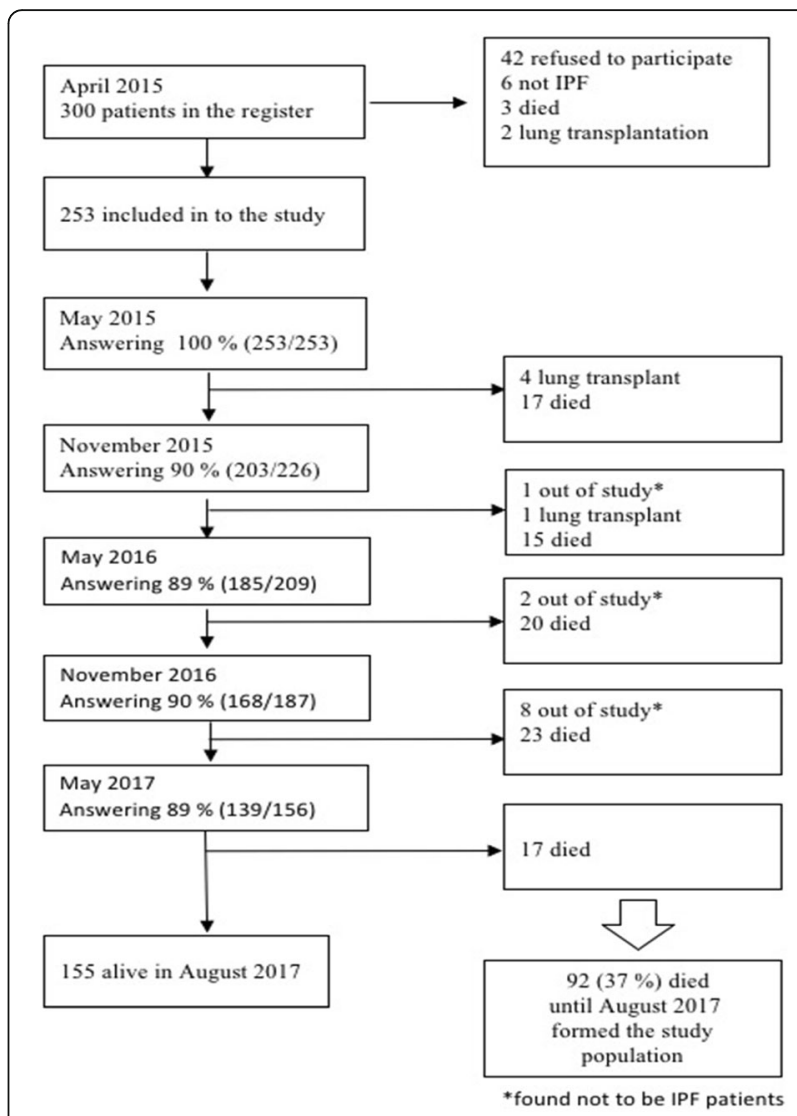

Fig. 1 Flowchart of patient recruitment and response rate

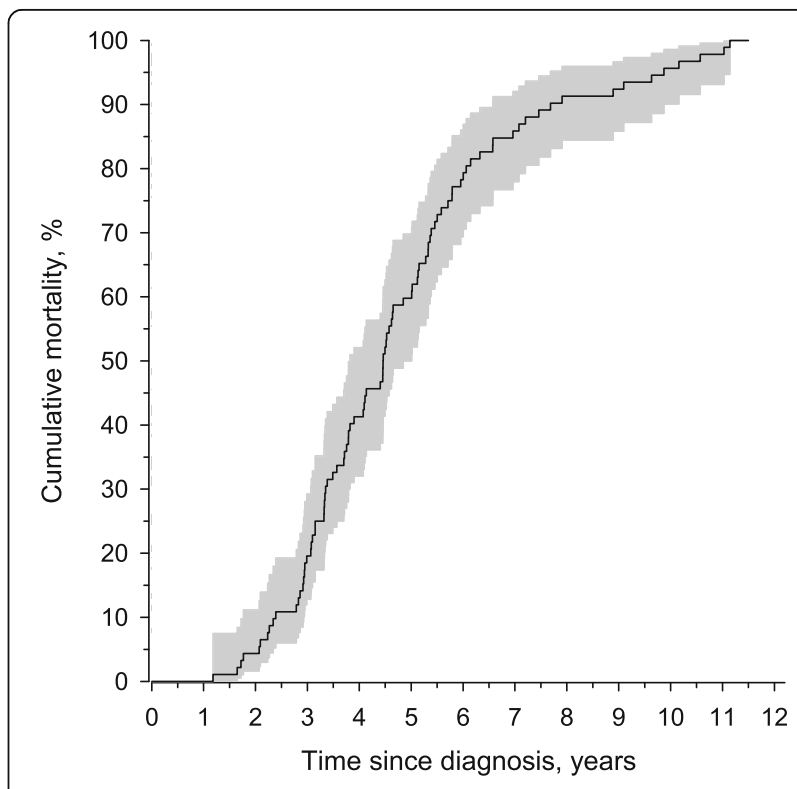

Fig. 2 Cumulative mortality after the diagnosis of IPF. Time-point of the diagnosis is marked with 0 and $95 \%$ confidence intervals with the grey area. Kaplan-Meier method was used to estimate the cumulative mortality 
Table 1 Patient characteristics

\begin{tabular}{|c|c|}
\hline Total number of patients & 92 \\
\hline Age, mean (range) & $75(57-92)$ \\
\hline Males n (\%) & $67(73)$ \\
\hline Duration of IPF in years, mean (SD) & $3.6(2.3)$ \\
\hline Education in years, mean (SD) & $10(3)$ \\
\hline Living alone, n (\%) & $31(34)$ \\
\hline Working, n (\%) & $4(4)$ \\
\hline \multicolumn{2}{|l|}{ Smoking status, n (\%) ${ }^{\mathrm{a}}$} \\
\hline Smoker & $6(7)$ \\
\hline Ex-smoker & $50(54)$ \\
\hline Never-smoker & $36(39)$ \\
\hline FVC (litres), mean (SD) ${ }^{b}$ & $2.9(0.8)$ \\
\hline FVC (\% of predicted), mean (SD) ${ }^{\mathrm{b}}$ & $78(16)$ \\
\hline Diffusion capacity, mean $(S D)^{c}$ & $54(13)$ \\
\hline \multicolumn{2}{|l|}{ Co-morbidities $^{\mathrm{e}}, \mathrm{n}(\%)$} \\
\hline Hypertension & $41(45)$ \\
\hline Coronary heart disease & $35(38)$ \\
\hline Diabetes & $24(26)$ \\
\hline Heart failure & $23(25)$ \\
\hline COPD & $20(22)$ \\
\hline Cancer & $16(17)$ \\
\hline Asthma & $8(9)$ \\
\hline No co-morbidities & $13(14)$ \\
\hline Number of co-morbidities, median (range) & $2(0-7)$ \\
\hline \multicolumn{2}{|l|}{ Place of death, $\mathrm{n}(\%)^{\mathrm{b}}$} \\
\hline Hospital $^{d}$ & $62(67)$ \\
\hline Home & $19(22)$ \\
\hline Nursing home & $4(5)$ \\
\hline Hospice & $3(3)$ \\
\hline
\end{tabular}

${ }^{a}$ smoking status, forced volume vital capacity (FVC) and diffusion capacity are recorded at the time of diagnosis and other factors at the time of the first questionnaire ${ }^{b}$ Data missing from 4 patients; ${ }^{c}$ data missing from 12 patients; ${ }^{d} 10$ in intensive care unit; $^{\mathrm{e}}$ patient-reported co-morbidities

before death. The decline in HRQOL was highly significant in all dimensions except in physical role, which showed very low scores by 24 months before death.

\section{Symptoms}

The intensity change of the symptoms measured by the ESAS during the last two years of life is presented in Fig. 4. The intensity of all symptoms except pain at rest and insomnia increased significantly near death. During the last six months of life, the mean NRS scores were as follows: 7.1 (SD 2.8) for breathlessness, 7.0 (SD 2.3) for tiredness, 6.0 (SD 2.5) for wellbeing, 6.0 (SD 3.0) for dry mouth, 5.8 (SD 2.9) for cough, 5.0 (SD 3.5) for pain with movement, 3.9 (SD 3.1) for insomnia, 3.9 (SD 2.9) for anxiety, 3.8 (SD 2.9) for depression, 3.6 (SD 3.1) for constipation, 3.4 (SD 3.3) for loss of appetite, 3.1 (SD 2.8) for pain at rest and 1.8 (SD 2.5) for nausea.

The steep change in the proportion of patients with MMRC scores $\geq 3$ (needing to stop walking after approximately $100 \mathrm{~m}$ or a few minutes because of breathlessness) during the last two years of life is shown in Fig. 5.

\section{Discussion}

In this study, we demonstrate a rapidly increasing impairment in HRQOL and escalating symptom burden in IPF patients approaching death. Low HRQOL together with severe breathlessness and fatigue were detected as early as two years before death. In addition, several dimensions of HRQOL declined further and the severity of many symptoms other than dyspnea increased during the last two years of life.

In the present study, HRQOL was considerably impaired two years prior to death in IPF patients. Physical role, i.e., role limitations due to physical health, was exceptionally low, but physical functioning, vitality and general health appeared to be below the general population level as well. Similar to our findings, an Australian registry study of 516 IPF patients reported HRQOL impairments in all domains, with the lowest score in activity, i.e., activities that cause or are limited by breathlessness [27]. The importance of decreased HRQOL was further highlighted in a recent study by Furukawa et al. that demonstrated that low HRQOL was actually an independent prognostic factor [28].

Although previous studies have demonstrated low HRQOL in IPF patients [10-12], none of them focused on the HRQOL from the aspect of approaching death in a follow-up setting. The uniqueness of this study stems from the continuing follow-up until death, and the subsequent finding of a salient decline in HRQOL during the last two years of life that was intensified near death. Deterioration was identified in all domains except physical role, which was already remarkably low two years before death. The most integral impairment was in physical, social and emotional functioning and vitality. In the Australian registry study, approximately one-third (38\%) of the IPF patients experienced clinically important differences in the decline of HRQOL during 12 months [27]. However, in that study, no HRQOL data was available from the period preceding death [27].

In lung cancer, functional concerns relating to physical movement or functioning predominate patients' symptom burden throughout the disease course and have a negative impact on HRQOL [42]. In addition, the severity of symptoms escalates, and the number of severe symptoms increases during the last three months of life [42-44]. A steep decline in HRQOL at the end-of-life is 

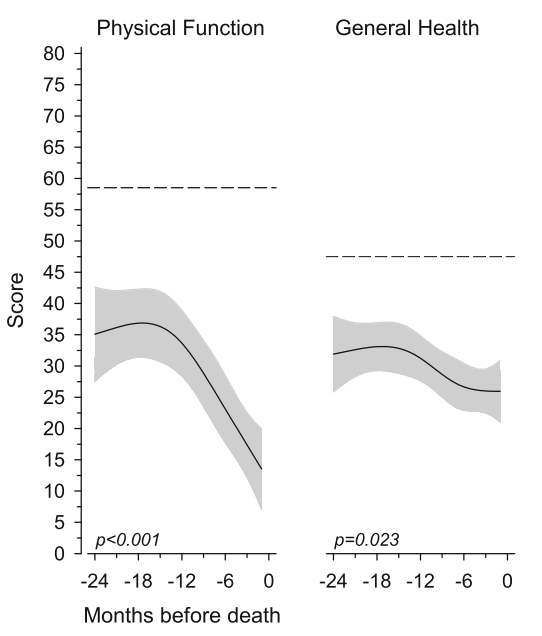
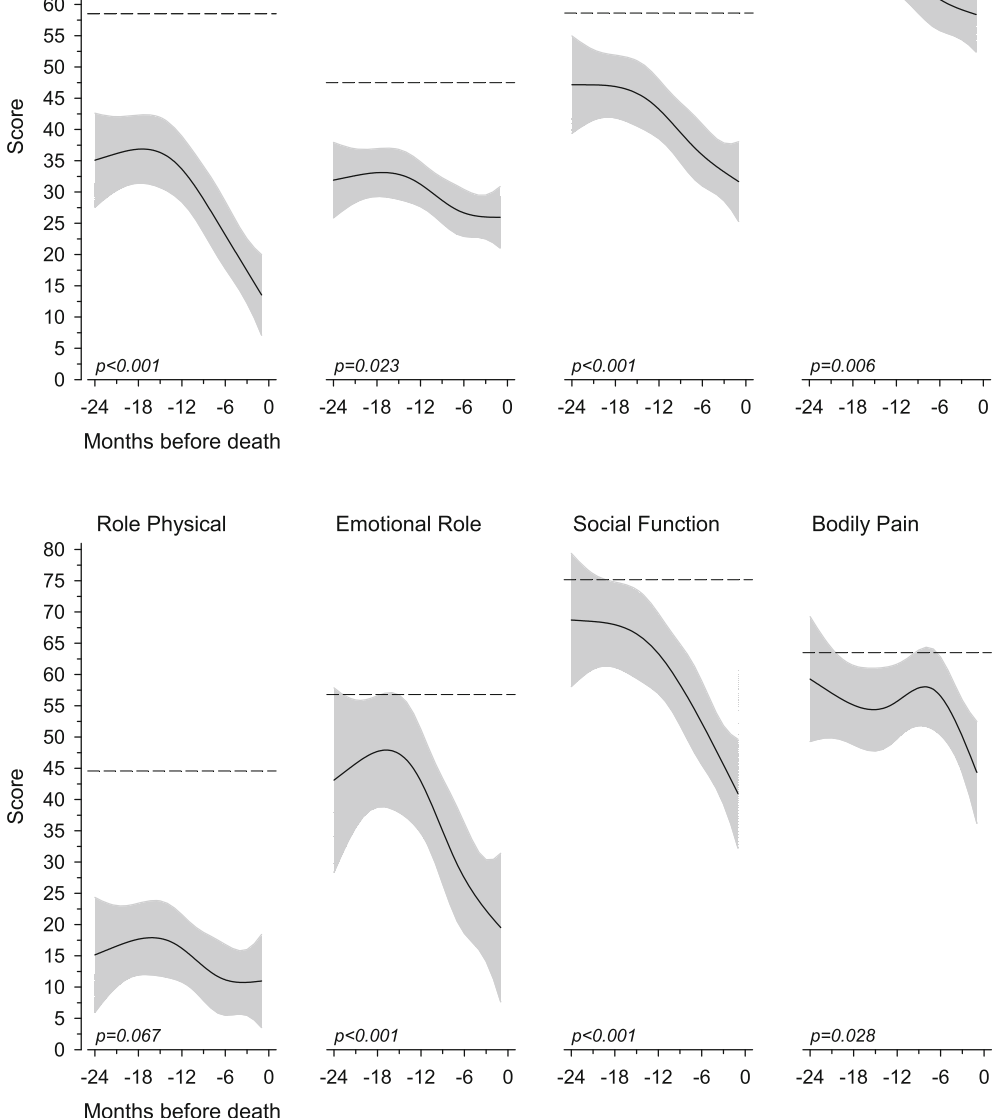

Emotional Role

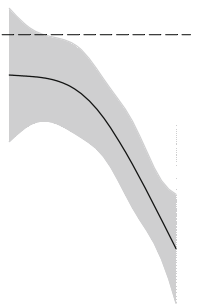

T24

$p<0.001$

$\begin{array}{ccccc}-24 & -18 & -12 & -6 & 0\end{array}$
Bodily Pain

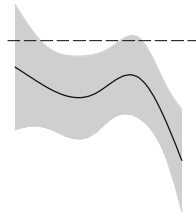

Mental Health

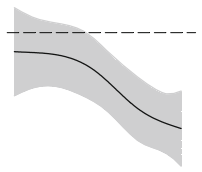

$\begin{array}{ccccc}p=0.028 & & & \\ -24 & -18 & -12 & -6 & 0\end{array}$

Fig. 3 Relationships between Health-related quality of life domains (RAND-36) two years before death. The curves were derived from a 5-knot restricted cubic splines regression models. The models were adjusted for age and gender. The grey area represents $95 \%$ confidence intervals. Dashed lines mark Finnish general population levels

typical in patients dying of cancer compared with other terminally ill patients $[45,46]$. In COPD patients, HRQOL gradually declines over time without a steeper decline at the end-of-life [47]. Our data imply that patients with IPF experience gradual impairments in HRQOL comparable to COPD patients but suffer from a pronounced, rapid deterioration in HRQOL during the last year of life, more closely resembling the disease trajectory of cancer.

Our results corroborate earlier findings on dyspnea and cough as the most severe symptoms in IPF patients regardless of the disease phase $[10,21,27,48]$. The intensity of dyspnea increased during the follow-up, being one of the most severe symptoms before death. In a previous IPF registry study, dyspnea yielded the strongest association with impaired HRQOL accounting for $71 \%$ of the variation in HRQOL [27]. In addition, exertion dyspnoea measured by the MMRC has been shown to correlate to HRQOL and symptom burden $[21,49]$.

In addition to dyspnea, other activity-limiting symptoms such as fatigue and pain in movement were among the most severe symptoms in our study. These activity-limiting symptoms can lead to physical inactivity and functional impairment, triggering a vicious circle with worse HRQOL. The intensity of depression and anxiety were, however, relatively mild two years before death, although these symptoms increased thereafter. In a recent study, depression was an independent predictor for HRQOL impairment, although it only accounted for $3.5 \%$ of the variation, whereas dyspnea accounted for 71\% [27]. Our results suggest that the relief of activity-limiting symptoms together with psychosocial support may improve HRQOL in advanced IPF. 


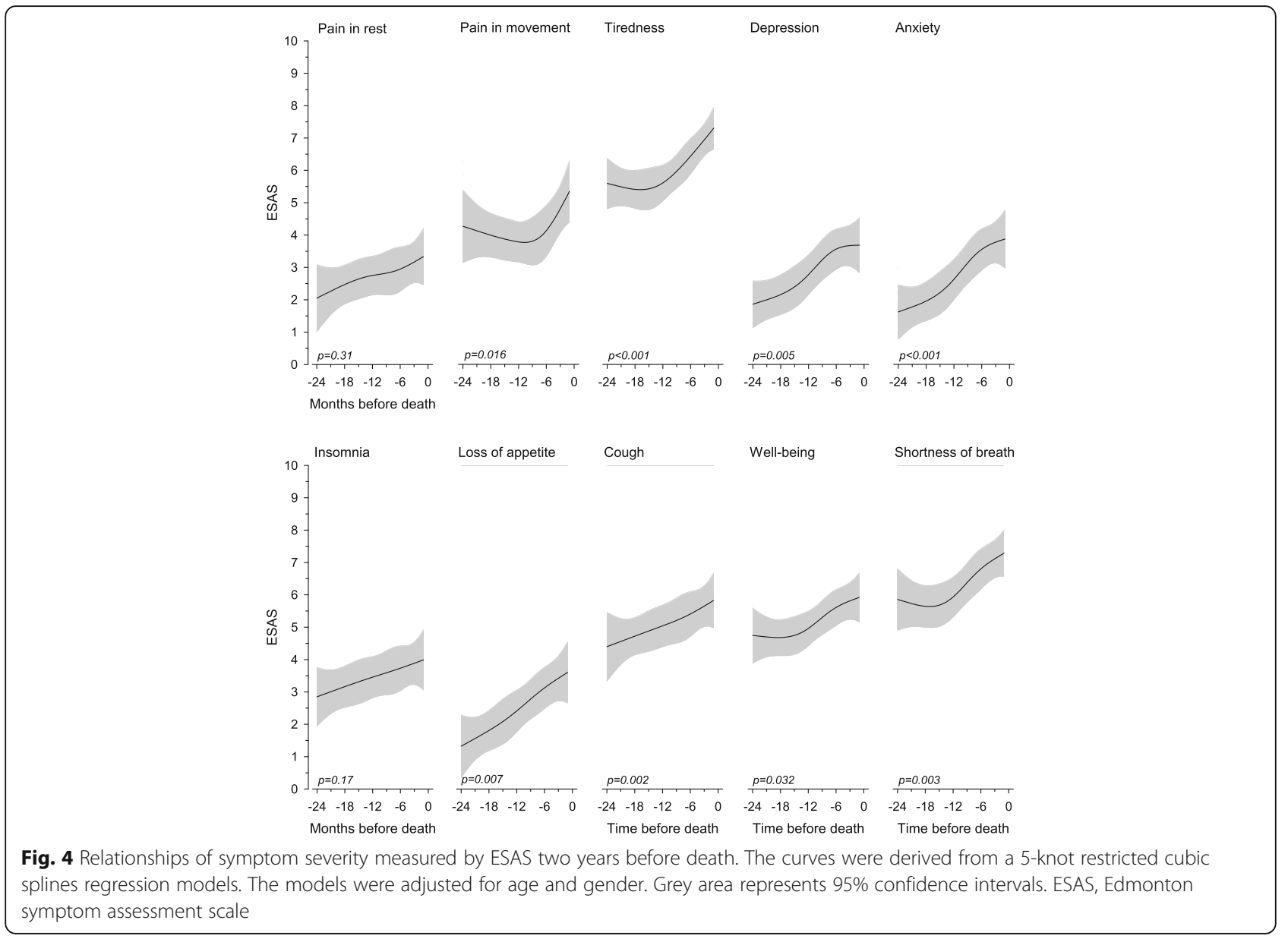

As discussed above, patients with advanced IPF, COPD and lung cancer suffer from a heavy symptom burden and deteriorating HRQOL. This calls for comprehensive symptom management and integrated palliative care concomitant with disease-modifying therapies [21, 27, 47, 50-52]. Early integrated palliative care for patients with lung cancer has shown substantial benefits, such as lower depression scores, higher HRQOL, better communication of end-of-life care preferences, less aggressive care at the end-of-life, and longer overall survival [51, 53]. Similarly, a randomised trial demonstrated better control of dyspnea and a survival benefit with integrated palliative care in patients with COPD and interstitial lung disease [54]. In addition to cancer patients, early integrated palliative care may reduce end-of-life acute care utilisation, and allow patients with IPF to die in their preferred locations [55-58]. Integrated palliative care in IPF patients seems to lower respiratory-related emergency room visits and hospitalisations and may allow more patients to die at home [55]. In this study, $67 \%$ of patients died in hospital and $11 \%$ in intensive care, which is in line with earlier findings, implying the necessity of improvements in advanced care planning and palliative care of patients with IPF [55, 59]. Our results provide insight into the most important needs of end-stage IPF patients and support the use of early-integrated palliative care, which should include symptom control beyond treatment for dyspnea and psychosocial support.

The relatively small study population limits our study, as did not having systematic follow-up data on lung function, which is at least partially due to the poor conditions of many of our patients. Our study is to our knowledge first to present follow-up data of HRQOL and symptoms for over two years before death. The strength is its real-life longitudinal design, with a unique cohort of IPF patients approaching death with an outstanding response rate, particularly considering the fact that some of the patients were probably too weak to respond during their final days or weeks of life. To our knowledge, this is the first study describing comprehensive patient-reported data on the HRQOL and symptom burden of IPF patients from the perspective of approaching death. 


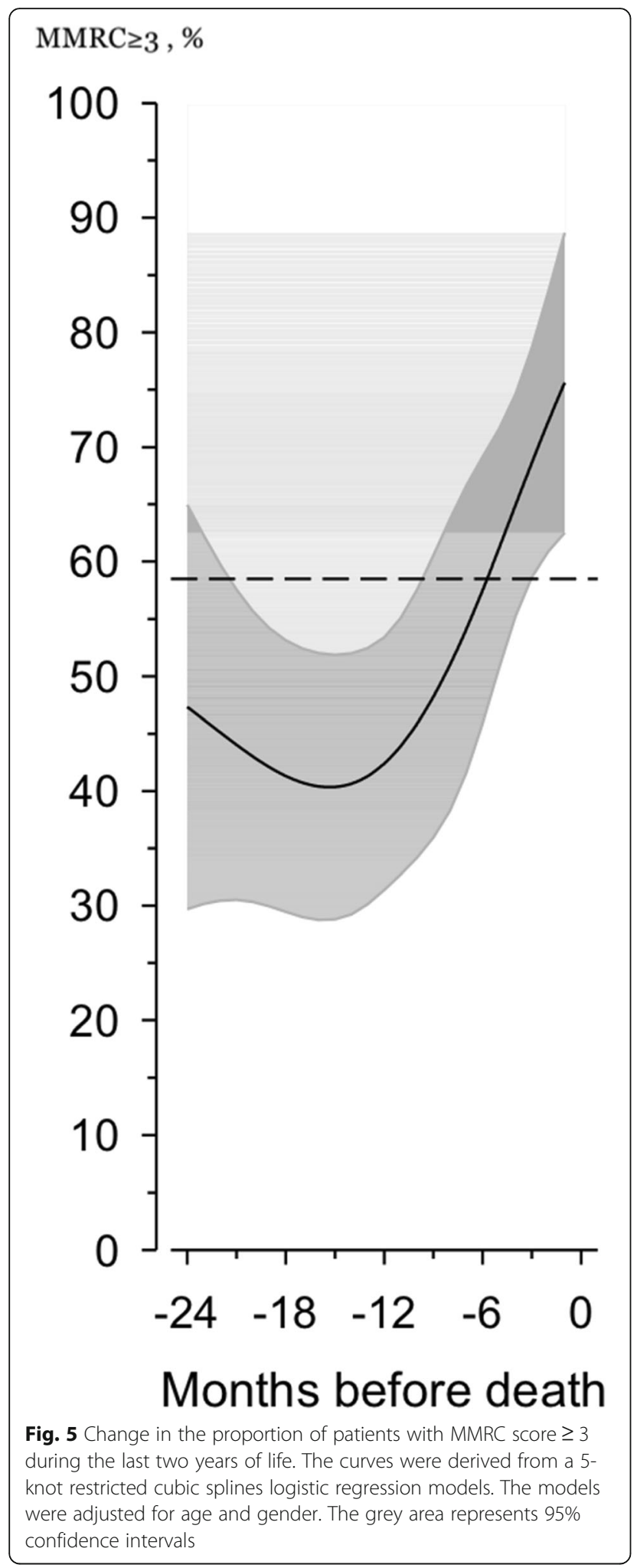

\section{Conclusion}

Patients with IPF suffer from exceptionally low HRQOL together with severe breathlessness and fatigue already two years before death. In addition, physical and emotional wellbeing further deteriorates near death concurrently with escalating overall symptom burden. In clinical practice, structured measurements of HRQOL and symptoms are necessary to guide high-quality early-integrated palliative care and end-of-life planning in IPF patients.

\section{Additional file}

Additional file 1: Disease and sociodemographic characteristics. The questionnaire used to collect disease and sociodemographic characteristics. (DOCX $35 \mathrm{~kb})$

\section{Abbreviations}

COPD: Chronic obstructive pulmonary disease; EOL: End-of-life;

ESAS: Modified Edmonton Symptom Assessment Scale; FVC: Forced vital capacity; HRQOL: Health-related quality of life; IPF: Idiopathic pulmonary fibrosis; IQR: Interquartile range; MMRC: Modified Medical Research Council Dyspnea Scale; NRS: Numeric rating scale; RAND-36: RAND 36-Item Health Survey; SD: Standard deviation; SGRQ: St Georges Respiratory Questionnaire

\section{Acknowledgements}

We are grateful for the patients that consented in participating this study. The authors express gratitude to the participants of the FinnishIPF consortium: Kaarteenaho R, Saarelainen S, Kankaanranta H, Böök A, Salomaa ER, Kaunisto J, Hodgson $U$ and Purokivi $M$. The authors are also immensely grateful to the numerous pulmonary physicians, who have contributed to the study by including patients and asking for informed consents: Vaden J, Pekonen $\mathrm{M}$, Tapanainen $\mathrm{H}$, Lajunen $\mathrm{H}$, Saarinen $\mathrm{A}$, Suuronen $\mathrm{U}$, Lammi L, Lehtonen $\mathrm{K}$, Männistö J, Salmi I, Torkko M, Torkko P, Erkkilä M, Andersen H, Jaakkola J, Rinne H, Alho M-L, Pietiläinen M, Toljamo T, Palomäki M, Nylund E, Ahonen E, Impola P, Saviaro S, Pusa L, Vilkman S, Ekroos H, Vuori P Hedman J, Lahti M and Mursu A.

\section{Funding}

The Academy of Finland, Sigrid Jusélius Foundation, Foundation of the Finnish Anti-Tuberculosis Association, Governmental subsidy for health sciences research have supported Lung Factor research group. Kaisa Rajala has received grants mentioned on conflicts of interest.

\section{Availability of data and materials}

Our dataset set is not publicly available due to the relatively small Finnish IPF population we could not guarantee individuals anonymity.

\section{Authors' contributions}

Study design: KR, JL, ES, TS, MM. Data Collection: KR, ES, MM. Data analysis: KR, JL, ES, TS, MM, HK. Written report: KR, JL, ES, TS, MM, HK. All authors read and approved the final manuscript. KR takes responsibility of the whole work

\section{Ethics approval and consent to participate}

The Finnish National Institute for Health and Welfare (Dnro THL/1 161/5.05.01/ 2012) approved the screening of hospital registries for patients with IPF. Helsinki University Central Hospital ethics committee approved this study (381/13/03/ 01/2014). All participating patients gave their written informed consent to participate to this specific study.

\section{Consent for publication}

Not applicable.

\section{Competing interests}

Kaisa Rajala has received grants from Foundation of the Finnish Anti-

Tuberculosis Association, Helsinki University Hospital Comprehensive Cancer 
Center and Väinö and Laina Kivi foundation. Other authors have no conflicts of interest affecting this work.

\section{Publisher's Note}

Springer Nature remains neutral with regard to jurisdictional claims in published maps and institutional affiliations.

\section{Author details}

${ }^{1}$ Department of Palliative Care, Comprehensive Cancer Center ${ }_{\text {"Helsinki }}$ University Hospital, Paciuksenkatu 21, Po BOX 180, FI-00290 Helsinki, Finland. ${ }^{2}$ Faculty of Medicine, University of Helsinki, Helsinki, Finland. ${ }^{3}$ Department of Oncology, Palliative Care Unit, Tampere University Hospital and Faculty of Medicine and Life Sciences, University of Tampere, Tampere, Finland. ${ }^{4}$ Faculty of Medicine, University of Helsinki, Helsinki, Finland. ${ }^{5}$ Primary Health Care Unit, Kuopio University Hospital, Finland and Folkhälsan Research Center, Helsinki, Finland. 'University of Helsinki and Helsinki University Hospital, Heart and Lung Center, Department of Pulmonary Medicine, Helsinki, Finland. ${ }^{7}$ Helsinki University Hospital, Comprehensive Cancer Center, Department of Palliative Care and Faculty of Medicine, University of Helsinki, Helsinki, Finland.

\section{Received: 10 July 2018 Accepted: 8 November 2018}

Published online: 20 November 2018

\section{References}

1. Raghu G, Collard HR, Egan JJ, Martinez FJ, Behr J, Brown KK, et al. An official ATS/ERS/JRS/ALAT statement: idiopathic pulmonary fibrosis: evidence-based guidelines for diagnosis and management. Am J Respir Crit Care Med. 2011 Mar:183(6):788-824.

2. Kaunisto J, Kelloniemi K, Sutinen E, Hodgson U, Piilonen A, Kaarteenaho R, et al. Re-evaluation of diagnostic parameters is crucial for obtaining accurate data on idiopathic pulmonary fibrosis. BMC Pulm Med [Internet]. 2015;15:92 Available from: https://doi.org/10.1186/s12890-015-0074-3.

3. Richeldi L, du Bois RM, Raghu G, Azuma A, Brown KK, Costabel U, et al. Efficacy and safety of Nintedanib in idiopathic pulmonary fibrosis. N Engl J Med [Internet]. 2014;370(22):2071-82 Available from: https://www.nejm.org/ doi/abs/10.1056/NEJMoa1402584.

4. King TE, Bradford WZ, Castro-Bernardini S, Fagan EA, Glaspole I, Glassberg MK, et al. A phase 3 trial of Pirfenidone in patients with idiopathic pulmonary fibrosis. N Engl J Med [Internet]. 2014;370(22):2083-92 Available from: http://www.nejm.org/doi/10.1056/NEJMoa1402582.

5. Behr J, Richeldi L. Recommendations on treatment for IPF. Respir Res [Internet]. 2013;14(Suppl. 1):S6 Available from: http://respiratory-research. com/content/14/S1/S6

6. Raghu G, Rochwerg B, Zhang Y, Garcia CAC, Azuma A, Behr J, et al. An official ATS/ERS/JRS/ALAT clinical practice guideline: treatment of idiopathic pulmonary fibrosis: an update of the 2011 clinical practice guideline. Am J Respir Crit Care Med. 2015;192(2):e3-19.

7. Kalluri M, Richman-Eisenstat J. Early and integrated palliative care to achieve a home death in idiopathic pulmonary fibrosis. J Pain Symptom Manage [Internet]. 2017;53(6):1111-5 Available from: https://doi.org/10.1016/j. jpainsymman.2016.12.344.

8. Raghu G, Richeldi L. Current approaches to the management of idiopathic pulmonary fibrosis. Respir Med [Internet]. 2017;129:24-30 Available from: https://doi.org/10.1016/j.rmed.2017.05.017

9. Caminati A, Cassandro R, Torre O, Harari S. Severe idiopathic pulmonary fibrosis: What can be done? Eur Respir Rev [Internet]. 2017;26(145) Available from: https://doi.org/10.1183/16000617.0047-2017.

10. Ahmadi Z, Wysham NG, Lundström S, Janson C, Currow DC, Ekström M. Endof-life care in oxygen-dependent ILD compared with lung cancer: a national population-based study. Thorax [Internet]. 2016;71(6):510-6 Available from: http://thorax.bmj.com/lookup/doi/10.1136/thoraxjnl-2015-207439.

11. Tomioka H, Imanaka K, Hashimoto K, Iwasaki $H$. Health-related quality of life in patients with idiopathic pulmonary fibrosis -cross-sectional and longitudinal study. Intern Med [Internet] 2007;46(18):1533-1542. Available from: http://joi.jlc.jst.go.jp/JST.JSTAGE/internalmedicine/46.6218?from= CrossRef\%5Cn. http://www.ncbi.nlm.nih.gov/pubmed/17878639.

12. Richeldi L, Cottin V, du Bois RM, Selman M, Kimura T, Bailes Z, et al. Nintedanib in patients with idiopathic pulmonary fibrosis: combined evidence from the TOMORROW and INPULSIS?? trials. Respir Med. 2015;113:74-9.
13. Kreuter M, Swigris J, Pittrow D, Geier S, Klotsche J, Prasse A, et al. Health related quality of life in patients with idiopathic pulmonary fibrosis in clinical practice: insights-IPF registry. Respir Res [Internet]. 2017;18(1):139 Available from: http:// respiratory-research.biomedcentral.com/articles/10.1186/s12931-017-0621-y.

14. Hubbard RB, Smith C, Le Jeune I, Gribbin J, Fogarty AW. The association between idiopathic pulmonary fibrosis and vascular disease: a populationbased study. Am J Respir Crit Care Med. 2008;178(12):1257-61.

15. Kreuter M, Ehlers-Tenenbaum S, Palmowski K, Bruhwyler J, Oltmanns U, Muley T, et al. Impact of comorbidities on mortality in patients with idiopathic pulmonary fibrosis. PLoS One. 2016;11(3):1-18.

16. Hyldgaard C, Hilberg O, Bendstrup E. How does comorbidity influence survival in idiopathic pulmonary fibrosis? Respir Med [Internet]. 2014;108(4): 647-53 Available from: https://doi.org/10.1016/j.rmed.2014.01.008.

17. Nathan SD, Basavaraj A, Reichner C, Shlobin OA, Ahmad S, Kiernan J, et al. Prevalence and impact of coronary artery disease in idiopathic pulmonary fibrosis. Respir Med [Internet]. 2010;104(7):1035-41 Available from: https:// doi.org/10.1016/j.rmed.2010.02.008

18. King CS, Nathan SD. Idiopathic pulmonary fibrosis: effects and optimal management of comorbidities. Lancet Respir Med. 2017;5(1):72-84.

19. Buendía-Roldán I, Mejía M, Navarro C, Selman M. Idiopathic pulmonary fibrosis: clinical behavior and aging associated comorbidities. Respir Med. 2017;129:46-52

20. Bajwah S, Higginson IJ, Ross JR, Wells AU, Birring SS, Riley J, et al. The palliative care needs for fibrotic interstitial lung disease: a qualitative study of patients, informal caregivers and health professionals. Palliat Med [Internet]. 2013;27(9):869-76 Available from: http://www.ncbi.nlm.nih.gov/ pubmed/23885010.

21. Yount SE, Beaumont $J$, Chen S-Y, Kaiser K, Wortman K, Van Brunt DL, et al. Health-related quality of life in patients with idiopathic pulmonary fibrosis. Lung [Internet]. 2016;194(2):227-34 Available from: http://link.springer.com/ 10.1007/s00408-016-9850-y.

22. Ryerson CJ, Berkeley J, Carrieri-KohIman VL, Pantilat SZ, Landefeld CS, Collard HR. Depression and functional status are strongly associated with dyspnea in interstitial lung disease. Chest. 2011;139(3):609-16.

23. Akhtar AA, Ali MA. Smith RP. Chron Respir Dis: Depression in patients with idiopathic pulmonary fibrosis; 2013.

24. Matsuda T, Taniguchi H, Ando M, Kondoh Y, Kimura T, Kataoka K, et al. Depression is significantly associated with the health status in patients with idiopathic pulmonary fibrosis. Intern Med [Internet]. 2017;56(13):1637-44 Available from: http://www.ncbi.nlm.nih.gov/pubmed/27274328.

25. van Manen MJG, Geelhoed JJM, Tak NC, Wijsenbeek MS. Optimizing quality of life in patients with idiopathic pulmonary fibrosis. Ther Adv Respir Dis [Internet]. 2017;11(3):157-69 Available from: https://www.ncbi.nlm.nih.gov/ pmc/articles/PMC5933652/.

26. Lee YJ, Choi SM, Lee YJ, Cho Y-J, II YH, Lee J-H, et al. Clinical impact of depression and anxiety in patients with idiopathic pulmonary fibrosis. PLoS One [Internet]. 2017;12(9):e0184300 Available from: http://dx.plos.org/10. 1371/journal.pone.0184300.

27. Glaspole IN, Chapman SA, Cooper WA, Ellis SJ, Goh NS, Hopkins PM, et al. Health-related quality of life in idiopathic pulmonary fibrosis: data from the Australian IPF registry. Respirology. 2017;22(5):950-6.

28. Furukawa T, Taniguchi H, Ando M, Kondoh Y, Kataoka K, Nishiyama O, et al. The St. George's Respiratory Questionnaire as a prognostic factor in IPF. Respir Res [Internet]. 2017;18(1):18 Available from: http://respiratory-research. biomedcentral.com/articles/10.1186/s12931-017-0503-3.

29. Hays RD, Morales LS. The RAND-36 measure of health-related quality of life, Ann Med [Internet]. 2001;33(5):350-7 Available from: http://www.ncbi.nlm. nih.gov/pubmed/11491194.

30. Aalto AM, Aro AR, Teperi J. RAND-36 terveyteen liittyvan elamanlaadun mittarina. Mittarin luotettavuus ja suomalaiset vaestoarvot. Stakes, Sos ja terveysalan tutkimus- ja Kehitt tutkimuksia. 1999;101:78.

31. Swigris JJ, Olson AL, Brown KK. Understanding and optimizing healthrelated quality of life and physical functional capacity in idiopathic pulmonary fibrosis. Patient Relat Outcome Meas [Internet]. 2016;7:29 Available from: https://www.ncbi.nlm.nih.gov/pmc/articles/PMC5519463/.

32. Swigris JJ, Brown KK, Behr J, du Bois RM, King TE, Raghu G, et al. The SF-36 and SGRQ: validity and first look at minimum important differences in IPF. Respir Med [Internet]. 2010;104(2):296-304 Available from: https://doi.org/10. 1016/j.rmed.2009.09.006.

33. Mahler DA, Wells CK. Evaluation of clinical for rating dyspnea. Chest. 1988; 93:580-6. 
34. Bestall JC, Paul EA, Garrod R, Garnham R, Jones PW, Wedzicha JA. Usefulness of the Medical Research Council (MRC) dyspnoea scale as a measure of disability in patients with chronic obstructive pulmonary disease. Thorax [Internet]. 1999;54(7):581-6 Available from: http://www.pubmedcentral.nih. gov/articlerender.fcgi?artid=1745516\&tool=pmcentrez\&rendertype=abstract.

35. Bruera E, Kuehn N, Miller MJ, Selmser P, Macmillan K. The Edmonton symptom assessment system (ESAS): a simple method for the assessment of palliative care patients. J Palliat Care. 1991;7(2):6-9.

36. Hui D, Bruera E. The Edmonton symptom assessment system 25 years later: past, present, and future developments. J Pain Symptom Manage [Internet]. 2017;53(3):630-43 Available from: https://doi.org/10.1016/j.jpainsymman. 2016.10.370

37. Chang VT, Hwang SS, Feuerman M. Validation of the Edmonton symptom assessment scale. Cancer. 2000;88(9):2164-71.

38. Hannon B, Dyck M, Pope A, Swami N, Banerjee S, Mak E, et al. Modified Edmonton symptom assessment system including constipation and sleep: validation in outpatients with cancer. J Pain Symptom Manage [Internet]. 2015; 49(5):945-52 Available from: https://doi.org/10.1016/j.jpainsymman.2014.10.013.

39. Oldenmenger WH, De Raaf PJ, De Klerk C, Van Der Rijt CCD. Cut points on 0-10 numeric rating scales for symptoms included in the Edmonton symptom assessment scale in cancer patients: a systematic review. J Pain Symptom Manage [Internet]. 2013;45(6):1083-93 Available from: https://doi. org/10.1016/j.jpainsymman.2012.06.007.

40. Harrell F. Regression modeling strategies with applications to linear models, logistic regression, and survival analysis. New York: Springer Series in Statistics; 2001.

41. StataCorp LP; Collage Station, Texas, USA; 2017.

42. LeBlanc TW, Nickolich M, Rushing CN, Samsa GP, Locke SC, Abernethy AP. What bothers lung cancer patients the most? A prospective, longitudinal electronic patient-reported outcomes study in advanced non-small cell lung cancer. Support Care Cancer. 2015;23(12):3455-63.

43. Iyer S, Taylor-Stokes G, Roughley A. Symptom burden and quality of life in advanced non-small cell lung cancer patients in France and Germany. Lung Cancer [Internet]. 2013;81(2):288-93 Available from: https://doi.org/10.1016/j. lungcan.2013.03.008.

44. Brown S, Thorpe H, Napp V, Brown J. Closeness to death and quality of life in advanced lung Cancer patients. Clin Oncol. 2007;19(5):341-8.

45. ManLois Downey MA, Ruth A, Engelberg RA. Quality-of-Life Trajectories at the End of Life: Assessments Over Time by Patients with and without Cancer. J Am Geriatr Soc. 2011:58(3):472-9.

46. Teno JM, Weitzen S, Fennell ML, Mor V. Dying trajectory in the last year of life: does Cancer trajectory fit other diseases? J Palliat Med [Internet]. 2001; 4(4):457-64 Available from: https://www.ncbi.nlm.nih.gov/pubmed/?term= teno+2001+Dying+trajectory+in+the+last+year+of+life\%3A+does+Cancer +trajectory+fit+other+diseases.

47. Habraken JM, van der Wal WM, ter Riet G, Weersink EJM, Toben F, Bindels PJE. Health-related quality of life and functional status in end-stage COPD: a longitudinal study. Eur Respir J [Internet]. 2011;37(2):280-8 Available from: http://erj.ersjournals.com/cgi/doi/10.1183/09031936.00149309.

48. Behr J, Kreuter M, Hoeper MM, Wirtz H, Klotsche J, Kosche D, et al. Management of patients with idiopathic pulmonary fibrosis in clinical practice: the INSIGHTS-IPF registry. Eur Respir J [Internet]. 2015;46(1):186-96 Available from: https://doi.org/10.1183/09031936.00217614

49. Rajala K, Lehto JT, Sutinen E, Kautiainen H, Myllärniemi M, Saarto T. mMRC dyspnoea scale indicates impaired quality of life and increased pain in patients with idiopathic pulmonary fibrosis. ERJ Open Res [Internet]. 2017; 3(4):00084-2017 Available from: http://openres.ersjournals.com/lookup/doi/ 10.1183/23120541.00084-2017.

50. Mohan A, Singh P, Singh S, Goyal A, Pathak A, Mohan C, et al. Quality of life in lung cancer patients: impact of baseline clinical profile and respiratory status: original article. Eur J Cancer Care (Engl). 2007;16(3):268-76.

51. Temel JS, Greer JA, Muzikansky A, Gallagher ER, Admane S, Jackson VA, et al. Early palliative Care for Patients with metastatic non-small-cell lung Cancer. N Engl J Med [Internet]. 2010;363(8):733-42 Available from: http://www. nejm.org/doi/abs/10.1056/NEJMoa1000678.

52. Rajala K, Lehto JT, Saarinen M, Sutinen E, Saarto T, Myllärniemi M. End-of-life care of patients with idiopathic pulmonary fibrosis. BMC Palliat Care [Internet]. 2016;15(1):85 Available from: http://www.ncbi.nlm.nih.gov/ pubmed/27729035.
53. Temel JS, Greer JA, El-Jawahri A, Pirl WF, Park ER, Jackson VA, et al. Effects of early integrated palliative care in patients with lung and gi cancer: a randomized clinical trial. J Clin Oncol. 2017;35(8):834-41.

54. Higginson IJ, Bausewein C, Reilly CC, Gao W, Gysels M, Dzingina M, et al. An integrated palliative and respiratory care service for patients with advanced disease and refractory breathlessness: a randomised controlled trial. Lancet Respir Med [Internet]. 2014;2(12):979-87 Available from: https://doi.org/10. 1016/S2213-2600(14)70226-7.

55. Kalluri M, Claveria F, Ainsley E, Haggag M, Armijo-Olivo S, Richman-Eisenstat J. Beyond Idiopathic Pulmonary Fibrosis diagnosis: Multidisciplinary care with an early integrated palliative approach is associated with a decrease in acute care utilization and hospital deaths. J Pain Symptom Manage [Internet]. 2017; Available from: http://www.ncbi.nlm.nih.gov/pubmed/ 29101086.

56. Bakitas MA, Tosteson TD, Li Z, Lyons KD, Hull JG, Li Z, et al. Early versus delayed initiation of concurrent palliative oncology care: patient outcomes in the ENABLE III randomized controlled trial. J Clin Oncol. 2015;33(13): 1438-45.

57. Marie B, Balan S, Brokaw FC, Seville J, Jay G. The project ENABLE ॥ randomized controlled trial to improve palliative Care for Patients with advanced Cancer. JAMA. 2009;302(7):741-9.

58. Zimmermann C, Swami N, Krzyzanowska M, Hannon B, Leighl N, Oza A, et al. Early palliative care for patients with advanced cancer: a clusterrandomised controlled trial. Lancet. 2014;383(9930):1721-30.

59. Lindell KO, Nouraie M, Klesen MJ, Klein S, Gibson KF, Kass DJ, et al. Randomised clinical trial of an early palliative care intervention (SUPPORT) for patients with idiopathic pulmonary fibrosis (IPF) and their caregivers: protocol and key design considerations. BMJ Open Respir Res [Internet]. 2018;5(1):e000272 Available from: http://bmjopenrespres.bmj.com/lookup/ doi/10.1136/bmjresp-2017-000272.

Ready to submit your research? Choose BMC and benefit from

- fast, convenient online submission

- thorough peer review by experienced researchers in your field

- rapid publication on acceptance

- support for research data, including large and complex data types

- gold Open Access which fosters wider collaboration and increased citations

- maximum visibility for your research: over $100 \mathrm{M}$ website views per year

At $\mathrm{BMC}$, research is always in progress.

Learn more biomedcentral.com/submissions 